\title{
LAMINAR FORCED CONVECTION IN HORIZONTAL CHANNEL WITH HEAT GENERATION PLATES COOLED BY WATER
}

\author{
M. C. da Silva, \\ and A. D. P. Novelli \\ Instituto Federal de Educação, Ciência e \\ Tecnologia de São Paulo \\ R. Diácono Jair de Oliveira, n. 1005, \\ Bairro Santa Rosa \\ ABSTRACT \\ This paper describes the study of the behavior of two-dimensional and \\ parallel horizontal flat plates with uniform internal heat generation \\ subjected to laminar forced convection of water. The governing equations \\ are solved numerically using the finite volume technique with Power-Law \\ interpolating scheme and the SIMPLE algorithm. After the simulations the \\ temperature and velocity fields were obtained for various plates spacing and \\ fluid inlet velocities, as well as the Nusselt number values.
}

Keywords: forced convection, numerical methods

\section{NOMENCLATURE}

$D \quad$ diameter, $\mathrm{m}$

$H \quad$ distance between plates, $\mathrm{m}$

$h$ heat transfer coefficient, $\mathrm{W}\left(\mathrm{m}^{2} \cdot \mathrm{K}\right)$

$k$ thermal conductivity, $\mathrm{W} /(\mathrm{m} \cdot \mathrm{K})$

$L \quad$ length of the channel, $m$

$N \quad$ dimensionless pressure head

$\mathrm{Nu} \quad$ Nusselt number

$P \quad$ dimensionless pressure

$p \quad$ pressure, $\mathrm{N} / \mathrm{m}^{2}$

$\mathrm{Pr} \quad$ Prandtl number

$q^{\prime \prime \prime} \quad$ internal heat generation of the plates, $\mathrm{W} / \mathrm{m}^{3}$

$R \quad$ conductivity ratio

Re Reynolds number

$T$ Temperature, $\mathrm{K}$

$t \quad$ plate thickness, $\mathrm{m}$

$U, V$ dimensionless velocities

$u, v$ velocities, $\mathrm{m} / \mathrm{s}$

$X, Y$ dimensionless distances

$x \quad$ horizontal distance, $\mathrm{m}$

$y \quad$ vertical distance, $\mathrm{m}$

\section{Greek symbols}

$\alpha \quad$ thermal diffusivity, $\mathrm{m}^{2} / \mathrm{s}$

$\theta \quad$ dimensionless temperature

$\mu \quad$ absolute viscosity, $\mathrm{Pa} \cdot \mathrm{s}$

$v$ fluid kinematic viscosity, $\mathrm{m}^{2} / \mathrm{s}$

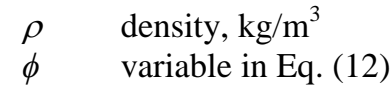
Subscripts
$b \quad$ bulk
$f \quad$ fluid
$h \quad$ hydraulic
$\max$ maximum
$o \quad$ inlet
$\mathrm{s} \quad$ surface
w wall

\section{Superscripts \\ $k \quad$ iteration}

\section{INTRODUCTION}

The technological development in recent years has achieved large advances in the area of electronic equipment. Therewith the study of heat removal generated by electronic equipments becomes extremely important in its design and operation. This importance is due to the fact that the highest temperature of the package must not exceed an upper limit.

There are several ways to extract heat generated from electronic devices (Incropera (1988) and Çengel 
(2007) which includes the natural and forced convection, using mainly air as coolant. The use of water in forced convection is suitable for electronic components with high heat fluxes. Bejan (1996) pursued to optimize the heat exchange in channels arranged side by side in a predetermined space. Leung et al. (2000) build up the numerical results of steady-state forced convection of laminar flow of air in horizontal printed circuit boards (PCB). They employed the configuration in which the upper plate was insulated (no heat flux) while the bottom one was taken to simulate the PCB. Silva and Ganzarolli (2002) determined the optimal spacing of plates with uniform internal generation of heat, cooled by air in laminar flow. They looked at various distances between the plates while maintaining the total pressure difference fixed in order to check which spacing is the maximum heat removal of the arrangement without exceeding the maximum temperature limit. Bhowmik et al. (2005) experimentally investigated convective heat transfer in a vertical rectangular channel cooled by water, covering the three convection modes (laminar, forced, natural and mixed convection) from a linear array of flush-mounted heat sources. It was obtained correlactions for relations using Nusselt number, Reynolds number and Grashof number. The work of Hamouche and Bessaih (2009) numerically investigated the two-dimensional laminar mixed convection to air in a horizontal channel with two identical protruding heat sources using the finite volume method and SIMPLER algorithm. Boutina and Bessaih (2011) studied the laminar mixed convection air cooling of two identical heat sources mounted in an inclined channel, obtaining correlations of Nusselt numbers of two components. The influence of Reynolds number and inclination angle on heat transfer was analysed, as well as the influence of the dimensions of the heat sources and the distance between them.

This work has a main goal to obtain the Nusselt numbers of an arrangement of horizontal parallel plates, with constant heat generation, for a range of values of distances between boards, inlet velocities and conductivity of the plates. The fluid is water and the flow regime is laminar. The governing equations were approximated numerically using the technique of finite volume (Patankar, 1980).

\section{PROBLEM FORMULATION}

The geometry analyzed in this work is shown in Fig. 1. The dotted region corresponds to the domain used at work. The gray part represents the plate area. The termophysical properties of the fluid are assumed to be constant. The governing equations in a dimensionless form for steady-state laminar, incompressible and two-dimensional fluid flow are:

Mass Conservation

$$
\frac{\partial U}{\partial X}+\frac{\partial V}{\partial Y}=0
$$

Momentum Conservation

$$
\begin{aligned}
& U \frac{\partial U}{\partial X}+V \frac{\partial U}{\partial Y}=-\frac{\partial P}{\partial X}+\frac{1}{\operatorname{Re}_{L}}\left(\frac{\partial^{2} U}{\partial X^{2}}+\frac{\partial^{2} U}{\partial Y^{2}}\right) \\
& U \frac{\partial V}{\partial X}+V \frac{\partial V}{\partial Y}=-\frac{\partial P}{\partial Y}+\frac{1}{\operatorname{Re}_{L}}\left(\frac{\partial^{2} V}{\partial X^{2}}+\frac{\partial^{2} V}{\partial Y^{2}}\right)
\end{aligned}
$$

Energy Conservation

$$
U \frac{\partial \theta}{\partial X}+V \frac{\partial \theta}{\partial Y}=\frac{1}{\operatorname{Re}_{L} \operatorname{Pr}}\left(\frac{\partial^{2} \theta}{\partial X^{2}}+\frac{\partial^{2} \theta}{\partial Y^{2}}\right)
$$

The energy equation for the solid region corresponds to:

$$
R\left(\frac{\partial^{2} \theta}{\partial X^{2}}+\frac{\partial^{2} \theta}{\partial Y^{2}}\right)+1=0
$$

And the dimensionless parameters in the above equations are defined by:

$$
\begin{aligned}
& X=\frac{x}{L} ; \quad Y=\frac{y}{L} ; \quad \operatorname{Re}_{L}=\frac{u_{o} L}{v} ; \\
& U=\frac{u}{u_{o}} ; \quad V=\frac{v}{u_{o}} ; \quad P=\frac{p}{\rho u_{o}^{2}} ; \\
& \operatorname{Pr}=\frac{v}{\alpha} ; \quad R=\frac{k_{w}}{k_{f}} ; \quad \theta=\frac{\left(T-T_{O}\right) k_{f}}{q^{\prime \prime \prime} L^{2}} ;
\end{aligned}
$$

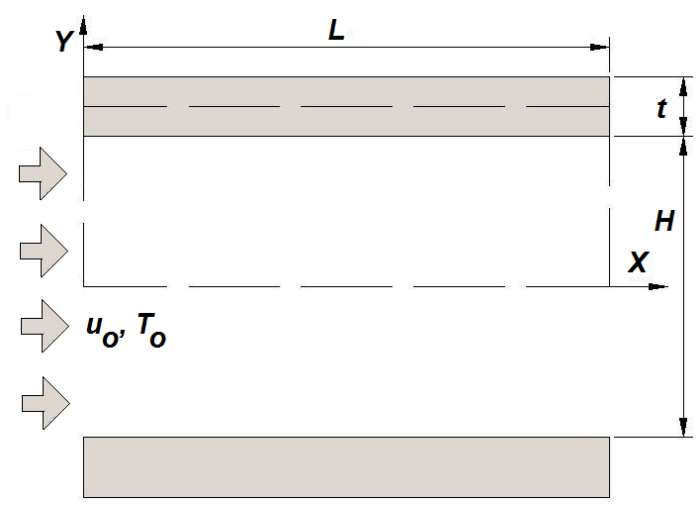

Figure 1. Geometry and Computational Domain.

The boundary conditions are:

$$
\left.\begin{array}{c}
X=0 \\
0 \leq Y<\frac{H}{2 L}
\end{array}\right\} U=1 ; \quad V=\theta=0
$$




$$
\begin{gathered}
\left.\begin{array}{c}
X=0 \\
\frac{H}{2 L} \leq Y<\frac{H+t}{2 L}
\end{array}\right\} U=V=\theta=0 \\
\left.\begin{array}{c}
X=1 \\
0 \leq Y<\frac{H}{2 L}
\end{array}\right\} \frac{\partial U}{\partial X}=\frac{\partial V}{\partial X}=\frac{\partial \theta}{\partial X}=0 \\
\left.\begin{array}{c}
X=1 \\
\begin{array}{c}
H \\
2 L
\end{array} \leq Y<\frac{H+t}{2 L}
\end{array}\right\} U=V=\frac{\partial \theta}{\partial X}=0 \\
\left.\begin{array}{c}
0 \leq X<1 \\
Y=0
\end{array}\right\} \frac{\partial U}{\partial Y}=\frac{\partial \theta}{\partial Y}=V=0 \\
\left.\begin{array}{c}
0 \leq X<1 \\
Y=\frac{H+t}{2 L}
\end{array}\right\} U=V=\frac{\partial \theta}{\partial Y}=0
\end{gathered}
$$

The local Nusselt number is defined as:

$$
N u_{x}=\frac{h \cdot D_{h}}{k_{f}}=\frac{q^{\prime \prime \prime} \cdot t \cdot D_{h}}{k_{f}}
$$

Where $D_{h}$ is hydraulic diameter (equal to $2 H$ for infinite parallel plates (Bejan (1995)) and the subscript $s$ denotes the surface of the plate, and $b$ the bulk temperature of the fluid, which can be expressed as follows:

$$
T_{b}=\frac{\int u T d y}{\int u d y}
$$
number:

Finally, the dimensionless form of the Nusselt

$$
N u_{X}=\frac{2 \cdot(t / L) \cdot(H / L)}{\left(\theta_{X, s}-\theta_{b}\right)}
$$
follows:

The average Nusselt number is calculated as

$$
\overline{N u}_{X}=\frac{\int N u X^{d X}}{\int d X}
$$

\section{NUMERICAL PROCEDURE}

The governing equations are solved using the finite volume method developed by Patankar (1980), with staggered grid for velocity field while the scalar quantities were stored in the center of these volumes. The convective therms of momentum and energy are approximated by Power-Law scheme. The SIMPLE algorithm is applied to solve the coupling of pressure- velocity. The Tri-Diagonal Matrix Algorithm (TDMA) method is employed to figure out the discretized set of equations and the programming language of the code is FORTRAN. The adopted convergence criterion is:

$$
\left|\frac{\phi^{k+1}-\phi^{k}}{\phi^{k}}\right| \leq 10^{-6}
$$

Where $\phi$ performs $U, V, \theta$ and the maximum residual in the continuity equation and $k$ the current iteration.

\section{Grid Independence Study}

Two uniform grids were analyzed in this work: $54 \times 402(Y \times X)$ and $106 \times 802(Y \times X)$. The problem choosed was to obtain the maximum temperature of the channel and the pressure at the centerline of the channel $(Y=0, X=1)$ for $H / L=0.25, R e_{L}=400, P r$ $=7$ and $R=10$. The results are summarized at Table 1 , where it is clear that the results for $54 \times 402$ points provides good results compared with the $106 \times 802$ with less computational effort.

Table 1. Results for the two grid points evaluated

\begin{tabular}{|c|c|c|c|}
\hline Grid & $\theta_{\max }$ & $P$ & Time (h) \\
\hline $54 \times 402$ & $1.30 \mathrm{E}-3$ & 0.722 & 1 hour \\
\hline $106 \times 802$ & $1.29 \mathrm{E}-3$ & 0.722 & 10 hours \\
\hline
\end{tabular}

The mesh 54 x 402 has 21708 control volumes, 400 in the horizontal direction and 52 the vertical one. The length of each control volume, both in $X$ and $Y$ direction, is 0.0025 . This is the value used for obtaining the others $H / L$ values in the present work.

\section{Code Validation}

The numerical code was compared with the numerical results of Silva and Ganzarolli (2002), which obtained maximum dimensionless temperature profiles as a function of a dimensionless pressure head $\mathrm{N}$ defined as:

$$
N=\left(\frac{\Delta p L^{2}}{\operatorname{Pr} \mu \alpha}\right)^{1 / 4}
$$

Results are shown in Fig. 2 for the dimensionless distance between the plates equal to $H / L=0.05$. The plate thickness adopted was $t / L=$ 0.006 and $R=30$. It was varied the Reynolds number to obtain the different pressure values. There is good agreement between the results of the present work and the ones of Silva and Ganzarolli (2002). 


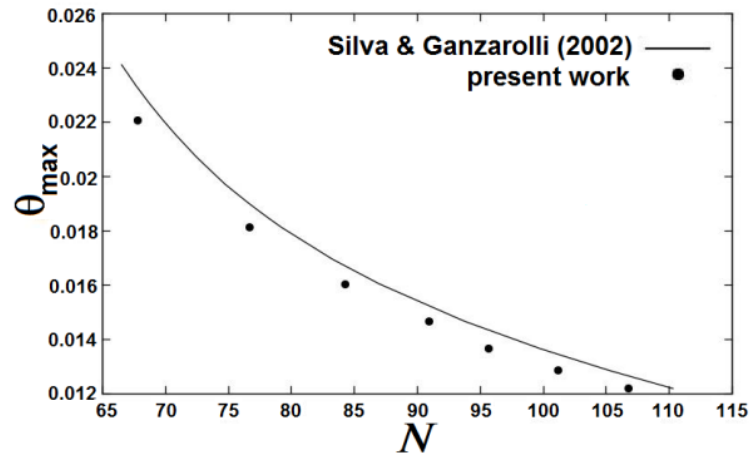

Figure 2. Comparison between the numerical results of maximum temperature in function of $N$.

\section{RESULTS AND DISCUSSION}

A numerical study has been carried out on laminar forced convection over a horizontal channel. Four distances between the boards $(H / L)$ were chosen, namely: $0.05,0.10,0.15$ and 0.2 . The $(H / L) R e_{L}$ values used were equal to: $100,200,300$, 400, 500, 600, 700 and 800. Each plate spacing was calculated the Local Nusselt Number. After integrating the Local Nusselt Number, the Average Nusselt Number was attained. The thickness of the plate adopted $(t / L \subset$ was equal to 0.01 . Two values of $R$ were specified: 10 and 20 . The Prandtl Number is 7 , which corresponds to water.

The conjugate problem (solid/fluid region) is adopted to solve the governing equations, and the temperature profile from energy equation is obtained separately from mass and momentum equations, after the determination of the velocity and pressure fields.

Figure 3 shows the Local Nusselt Number along the plate surface in the horizontal direction $(X)$ for the various $H / L$ distances and $R=10$. It is clear the effect of the velocity in the convective heat transfer. The increase of the Reynolds Number corresponds to the growing of the Local Nusselt Number. It is the indication of the decrease of the temperature with growing of mass flow inside the channel. This effect is also observed in the Average Nusselt Number (Table 2). Figure 4 presents the Local Nusselt Number for $R=20$, with the objective to analyze the effect of the rise of the conductivity in heat transfer. The results denote that the augment of $k_{w}$ leads to less thermal resistance of conduction, which corresponds a lower Nusselt Number. However, to change the value of $R$ from 10 to 20 does not correspond to the values of Nusselt Number decay from half of the value.

Table 2 presents the results of Average Nusselt Number for the several $H / L$ values $(R=10)$ and Tab. 3 exhibits the results for $R=20$. In both cases the raising of the mass flow it provides the increase of Nusselt Number, and the same behavior is observed when increasing the distance between the plates. As explained, the increases in $R$ factor indicates a diminution in Average Nusselt Number.

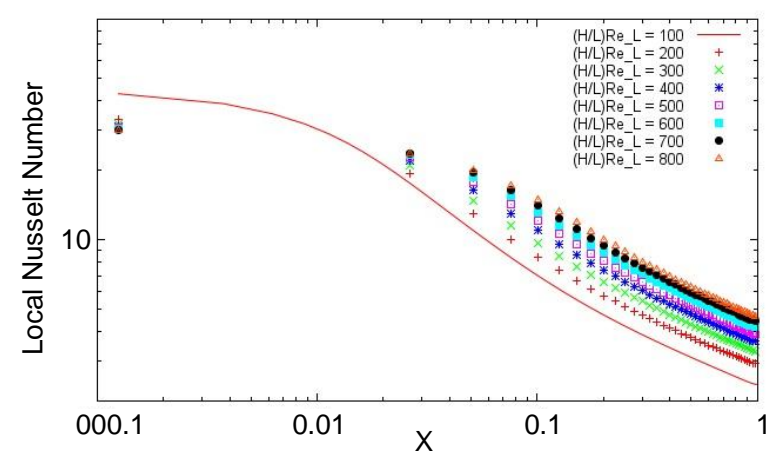

(a)

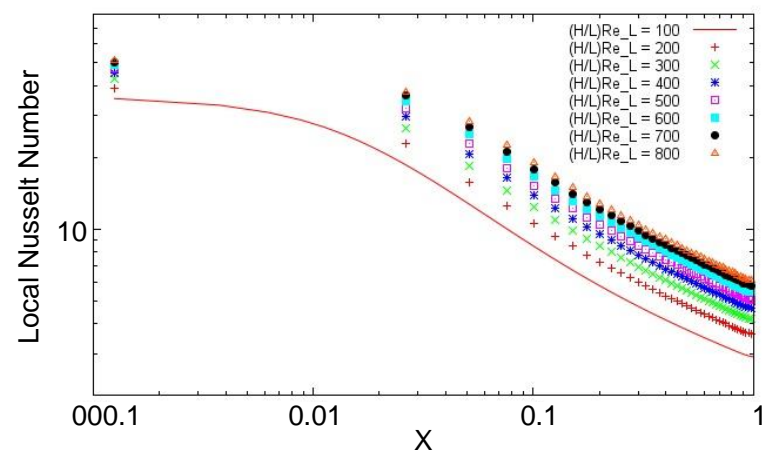

(b)

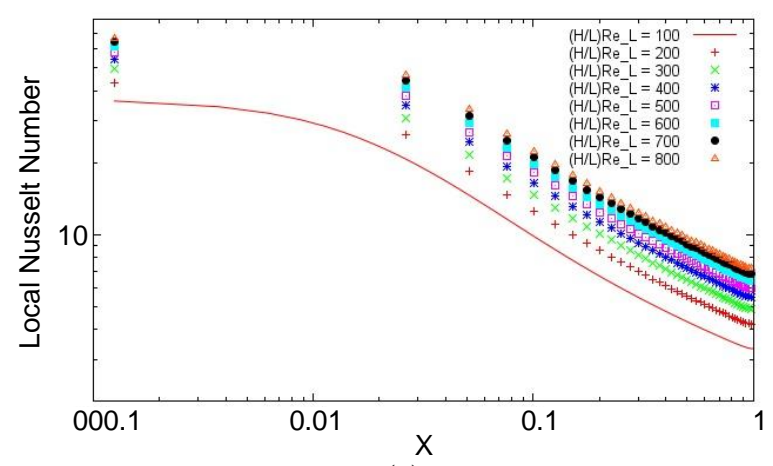

(c)

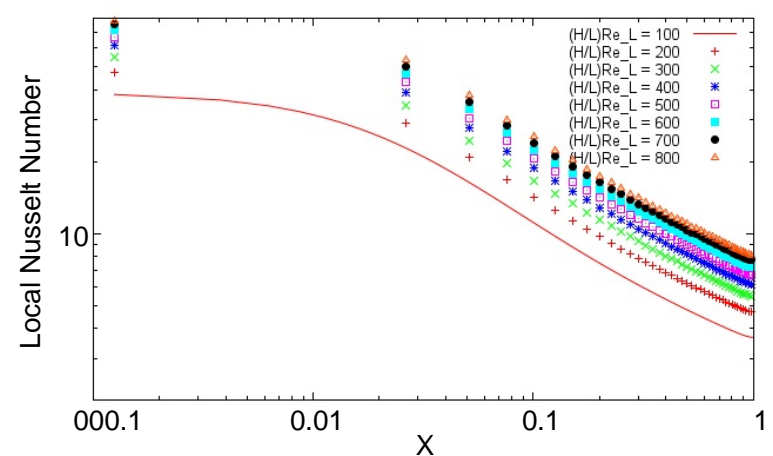

(d)

Figure 3. Local Nusselt Number $(R=10)$ : (a) $H / L=$ 0.05 , (b) $H / L=0.10$, (c) $H / L=0.15$, (d) $H / L=0.20$.

As examples of the decay of temperature for the data obtained the value for temperature at $X=1$ and $Y$ $=0$ was equal to $1.6 \cdot 10^{-6}\left(R=10,(H / L) R e_{L}=100\right.$ and $H / L=0.2)$. At the same position $(X=1$ and $Y=0)$ the 
value of the temperature was equal to $2.2 \cdot 10^{-19}(R=$ 10, $(H / L) R e_{L}=800$ and $\left.H / L=0.2\right)$. The same behavior is observed when increased the value of $R$.

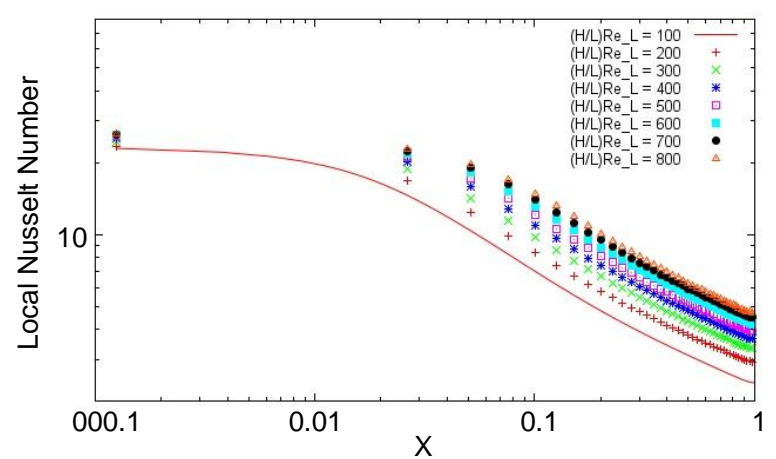

(a)

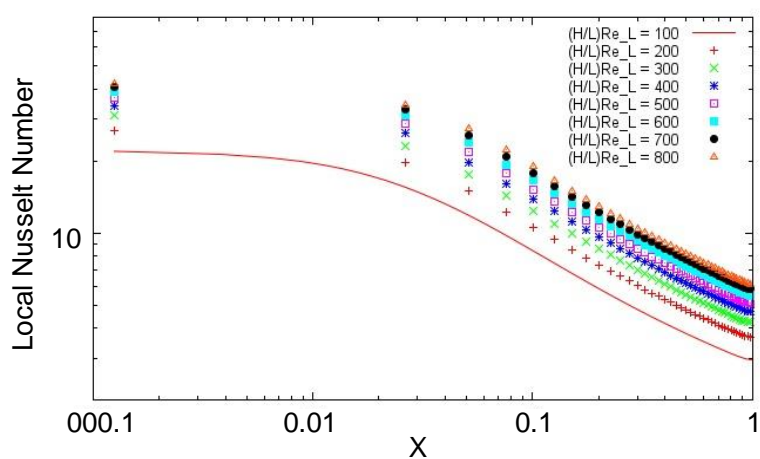

(b)

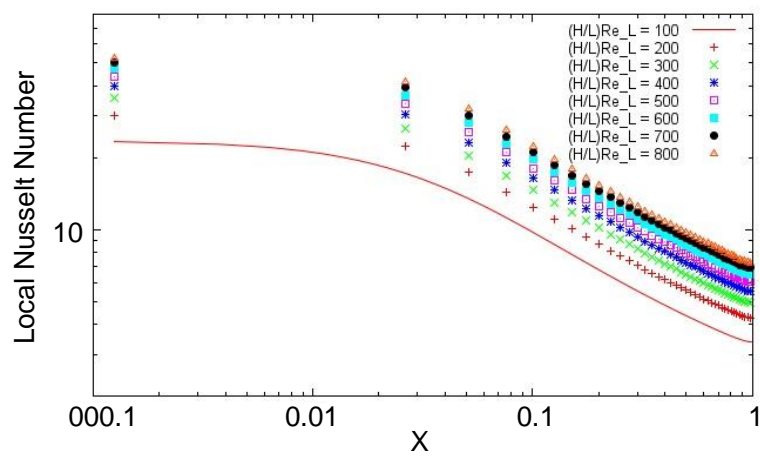

(c)

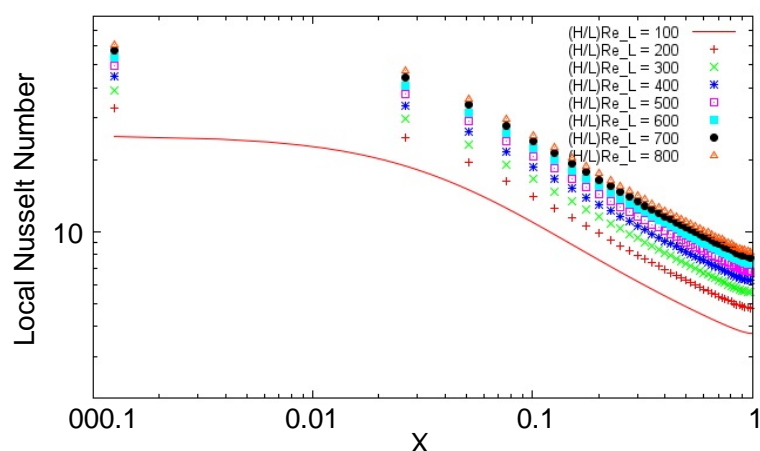

(d)

Figure 4. Local Nusselt Number $(R=20)$ : (a) $H / L=$ 0.05 , (b) $H / L=0.10$, (c) $H / L=0.15$, (d) $H / L=0.20$.
Table 2. Average Nusselt Number in function of $H / L$ $(R=10)$

\begin{tabular}{|c|c|c|c|c|}
\hline & \multicolumn{4}{|c|}{$H / L$} \\
\hline$(H / L) R e_{L}$ & 0.05 & 0.10 & 0.15 & 0.20 \\
\hline 100 & 4.4322 & 5.1694 & 5.8856 & 6.5164 \\
\hline 200 & 5.1685 & 6.4316 & 7.4819 & 8.3784 \\
\hline 300 & 5.8350 & 7.4508 & 8.7448 & 9.8378 \\
\hline 400 & 6.4122 & 8.3199 & 9.8180 & 11.0759 \\
\hline 500 & 6.9236 & 9.0862 & 10.7655 & 12.1692 \\
\hline 600 & 7.3850 & 9.7764 & 11.6212 & 13.1580 \\
\hline 700 & 7.8072 & 10.4076 & 12.4061 & 14.0662 \\
\hline 800 & 8.1979 & 11.9917 & 13.1337 & 14.9101 \\
\hline
\end{tabular}

Table 3. Average Nusselt Number in function of $H / L$ $(R=20)$.

\begin{tabular}{|c|c|c|c|c|}
\hline & \multicolumn{4}{|c|}{$H / L$} \\
\hline$(H / L) R e_{L}$ & 0.05 & 0.10 & 0.15 & 0.20 \\
\hline 100 & 4.1987 & 4.9747 & 5.6762 & 6.3040 \\
\hline 200 & 5.0202 & 6.2451 & 7.2612 & 8.1478 \\
\hline 300 & 5.7157 & 7.2624 & 8.5105 & 9.5902 \\
\hline 400 & 6.3139 & 8.1316 & 9.5734 & 10.8149 \\
\hline 500 & 6.8424 & 8.9008 & 10.5139 & 11.8978 \\
\hline 600 & 7.3182 & 9.5961 & 11.3655 & 12.8789 \\
\hline 700 & 7.7528 & 10.2342 & 12.1488 & 13.7820 \\
\hline 800 & 8.1541 & 10.8262 & 12.8773 & 14.6230 \\
\hline
\end{tabular}

\section{CONCLUSIONS}

It was obtained numerically values of the Nusselt Number (local and average) for a laminar forced convection of water in a two-dimensional horizontal channel composed by flat plates with internal heat generation. Results shown that the increase in Reynolds Number, for a fixed plates spacing, denotes a growth of Nusselt Number. The same effect occurs at the rise of plates spacing, for a fixed Reynolds Number. It was noticed that the increment of factor $R$ corresponds to a reduction of the Nusselt Number.

\section{REFERENCES} Wiley.

Bejan, A., 1995, Convection Heat Transfer,

Bejan, A., 1996, Geometric Optimization of Cooling Techniques in: Air Cooling Technology for Electronic Equipment, CRC Press, New York, Edited by Kim, S. J., and Lee, S. W.

Bhowmik, H., Tso, C. P., Tou, K. W., and Tn, F. L, 2005, Convection Heat Transfer from Discrete Heat Sources in a Liquid Cooled Rectangular Channel, Applied Thermal Engineering, Vol. 25, pp. 2532-2542.

Boutina, L., and Bessaih, R., 2011, Numerical Simulation of Mixed Convection Air-Cooling of Electronic Components Mounted in an Inclined Channel, Applied Thermal Engineering, Vol. 31, pp. 2052-2062.

Çengel, Y. A., 2007, Heat and Mass Transfer: A Practical Approach, McGraw-Hill.

Hanouche, A., and Bessaih, R., 2009, Mixed 
Convection Air Cooling of Protuding Heat Sources Mounted in a Horizontal Channel, International Communications in Heat and Mass Transfer, Vol. 36, pp. 841-849.

Incropera, F. P., 1988, Convection Heat Transfer in Electronic Equipment Cooling, ASME Journal of Heat Transfer, Vol. 110, pp. 1097-1111.

Leung, C. W., Chen, S., and Chan, T. L., 2000, Numerical Simulation of Laminar Forced Convection in Air-Cooled Horizontal Printed Circuit Board Assembly, Numerical Heat Transfer Part A, Vol. 37, Issue 4, pp. 373-393.

Patankar, S. V., 1980, Numerical Heat Transfer and Fluid Flow, McGraw-Hill.

Silva, M. C., and Ganzarolli, M. M., 2002, Determination of The Optimal Spacing in a Stack of Parallel Heat Generating Boards, in: Proceedings of the 9th Brazilian Congress of Thermal Sciences and Engineering (ENCIT 2002), Caxambu, Brazil. 